\title{
Application of an advanced fuzzy logic model for landslide susceptibility analysis
}

\author{
Biswajeet Pradhan \\ Institute of Cartography, Faculty of Forestry, Geo and Hydro-Science, \\ Dresden University of Technology, 01062 Dresden, Germany, \\ Tel: +49-351 463 33099; Fax: +49-351 46337028
}

E-Mail: Biswajeet.Pradhan@mailbox.tu-dresden.de/biswajeet@mailcity.com

\author{
Received: 20-05-2009 \\ Accepted: 11-02-2010
}

\begin{abstract}
The aim of this study is to evaluate the susceptibility of landslides at Klang valley area, Malaysia, using a Geographic Information System (GIS) and remote sensing. Landslide locations were identified in the study area from interpretation of aerial photographs and from field surveys. Topographical and geological data and satellite images were collected, processed, and constructed into a spatial database using GIS and image processing. A data derived model (frequency ratio) and a knowledge-derived model (fuzzy operator) were combined for landslide susceptibility analysis. The nine factors that influence landslide occurrence were extracted from the database and the frequency ratio coefficient for each factor was computed. Using the factors and the identified landslide, the fuzzy membership values were calculated. Then fuzzy algebraic operators were applied to the fuzzy membership values for landslide susceptibility mapping. Finally, the produced map was verified by comparing with existing landslide locations for calculating prediction accuracy. Among the fuzzy operators, in the case in which the gamma operator $(\lambda=0.8)$ showed the best accuracy $(91 \%)$ while the case in which the fuzzy algebraic product was applied showed the worst accuracy $(79 \%)$.
\end{abstract}

Keywords: Fuzzy relations; Fuzzy membership; Landslide susceptibility; GIS; Remote sensing; Klang valley; Maalysia.

\section{Introduction}

Landslide presents a significant constraint to development in many parts of Malaysia. Damages and losses are regularly incurred because, historically, there has been too little consideration of the potential problems in land use planning and slope management. Landslides are mostly occurred in Malaysia mainly due to heavy rainfall. In recent years greater awareness of landslide problems has led to significant changes in the control of development on unstable land, with the Malaysian government and highway authorities stressing the need for local planning authorities to take landslide into account at all stages of the landslide susceptibility mapping process. So far, few attempts have been made to predict these landslides or preventing the damage caused by them. Through this prediction model, landslide damage could be greatly decreased. Through scientific analysis of landslides, we can assess and predict landslide-susceptible areas, and thus decrease landslide damage through proper preparation. To achieve this aim, landslide susceptibility analysis techniques have been applied, and verified in the study area using fuzzy logic operators.

Landslide occurrence areas were detected in the Klang valley area, Malaysia by interpretation of aerial photographs and field surveys. A landslide map was prepared from aerial photographs, in combination with the GIS, and this were used to evaluate the frequency and distribution of shallow landslides in the area. Topography and lithology databases were constructed 
and lineament, land cover and vegetation index value extracted from Landsat TM satellite image for the analysis. Then, the calculated and extracted factors were converted to a $10 \mathrm{~m} \times 10 \mathrm{~m}$ grid (ARC/INFO GRID type). Fuzzy operator model was applied using the database and landslide susceptibility map was created. Finally, the map was verified and compared using known landslide locations for quantitative verification. In the study, Geographic Information System (GIS) software, ArcView 3.2, and ArcGIS 9.0 version software packages were used as the basic analysis tools for spatial management and data manipulation.

Using the factors and the detected landslide, the relationships were calculated using the frequency ratio, one of the probabilistic models. Then, the fuzzy membership values were also calculated using the frequency ratio. The fuzzy membership values were combined using the fuzzy and, fuzzy or, fuzzy algebraic product, fuzzy algebraic sum and fuzzy gamma operators (13 cases) for landslide susceptibility mapping. Finally, the map was verified by comparing with existing landslide locations for calculating prediction accuracy.

Many studies have been carried out applying GIS to landslide susceptibility analysis. Guzzetti et al. (1999) ${ }^{1}$ summarized many landslide susceptibility evaluation studies. In addition, many studies on landslide susceptibility mapping using probabilistic methods have been described ${ }^{2-17}$. Many authors have applied the logistic regression method for landslide susceptibility mapping ${ }^{18-27}$. Other methods like geotechnical and the safety-factor models have been applied in different $\operatorname{areas}^{28-29}$. New statistical approaches such as data mining, fuzzy logic, and artificial neural network methods have been applied in various case studies ${ }^{30-55}$. In this paper, a total of 9 landslide conditioning factors were derived from the topographical, geological and geomorphological data which were only available for the study area. Pradhan and Lee (2009) $)^{36-39}$ worked on the different regions of Malaysia and found these parameters are quite suitable for the regional landslide susceptibility analysis.

\section{Study area}

The eastern part of Selangor state has suffered much landslide damage following heavy rains, was selected as a suitable pilot area to evaluate frequency and distribution of landslides (Fig. 1). Selangor is one of the
13 states of the Federation of Malaysia. The study area is located on the south west coast of the Malaysian peninsular. It is bounded to the north and east by the state of Perak, Pahang and to the south by Negeri Sembilian, Melaka. The study area is located approximately between $3^{\circ} 23^{\prime} 53.6^{\prime \prime} \mathrm{E}$ and $3^{\circ} 45^{\prime}$ 18.05' E and $101^{\circ} 30^{\prime} 55.33^{\prime \prime} \mathrm{N}$ and $101^{\circ} 3^{\prime} 36.3^{\prime \prime} \mathrm{N}$. The landuse at the study area is mainly peat swamp forest, plantation forest, inland forest, scrub, grassland and exmining area. The landform of the area ranges from very flat terrain, especially for the peat swamp forest, ex mining, grassland and scrub area, to quite hilly area for the natural forest ranging between 0 - 420 meter above sea level. Based on Malaysian Meteorological Services Department, the temperature of northern part of Selangor is between $29^{\circ} \mathrm{C}$ to $32^{\circ} \mathrm{C}$ and mean relative humidity of $65 \%$ to $70 \%$. The highest temperature is between April to June while the relative humidity is lowest in June, July and September. The rainfall about $58 \mathrm{~mm}$ to $240 \mathrm{~mm}$ per month was recorded in the study area (Tanjung Karang weather station provided by Malaysian Meteorological Services Department).

\section{GIS database construction}

To apply the fuzzy model, a spatial database that considers landslide-related factors was designed and constructed. These data are available in Malaysia either as paper or as digital maps. The spatial database constructed is listed in Table 1. The lineament and land cover were detected from satellite images such as Landsat TM (Thematic Mapper) images. There were ten landslide inducing factors considered in calculating the fuzzy membership function. These factors were transformed into a vector-type spatial database using the GIS. For the DEM creation, $10 \mathrm{~m}$ interval contours and survey base points showing the elevation values were extracted from the 1:25,000-scale topographic maps and TIN (Triangulated Irregular Network) was made using the elevation value. A DEM (digital elevation model) was made using the IDW (inverse distance weighting) interpolation method with $10 \mathrm{~m}$ resolution. Using this DEM, slope angle, slope aspect, and plan curvature were calculated. The plan curvature is prepared using the DEMAT extension of the ArcView 3.2. In addition, the distance from drainage was calculated using the topographic database. The drainage buffer was calculated at $100 \mathrm{~m}$ intervals and classified into 10 equal area classes. The lithology map is prepared from a 
1:63,300-scale geological map. A structural geologist interpreted the Spot 5 image by photo interpretation and detected the lineaments. Further the distance from lineament is calculated based on the Euclidean distance method in ArcView 3.2. The lineament buffer was calculated in $100 \mathrm{~m}$ intervals and classified into 10 equal area classes. Landuse map was prepared using Landsat TM image (30 $\mathrm{m}$ spatial resolution) using unsupervised classification (ISODATA) method and field survey. There were 11 landuse classes identified, such as urban, water, forest, agriculture, and barren area. The soil map was digitised from a 1:100,000-scale soil map (Source: Department of Irrigation and Drainage, Malaysia).

Finally, the Normalized Difference Vegetation Index (NDVI) map was generated from SPOT 5 (2.5 m spatial resolution) satellite images. The NDVI value was calculated using the formula NDVI $=(I R-R) /(I R+$ $R$ ), where IR is the energy reflected in the infrared portion of the electromagnetic spectrum, and $\mathrm{R}$ is the energy reflected in the red portion of the electromagnetic spectrum. The NDVI is useful in delineating vegetation. Overall, the Klang valley data set comprised 12131 rows by 21258 columns, for a total pixel number of 257880,798 . Landslides had occurred in 326 of these pixels.

\section{Landslide susceptibility analysis using fuzzy model}

The fuzzy set theory introduced by Zadeh (1965) $)^{40-44}$ is one of the tools used to handle the complex problems. Therefore, the fuzzy set theory has been commonly used for many scientific studies in different disciplines. The idea of fuzzy logic is to consider the spatial objects on a map as members of a set. In the classical set theory, an object is a member of a set if it has a membership value of 1 , or is not a member if it has a membership value of 0 . In the fuzzy set theory, membership can take on any value between 0 and 1 reflecting the degree of certainty of membership. The fuzzy set theory employs the idea of a membership function that expresses the degree of membership with respect to some attribute of interest. With maps, generally, the attribute of interest is measured over discrete intervals, and the membership function can be expressed as a table relating map classes to membership values. Fuzzy logic is attractive because it is straightforward to understand and implement. It can be used with data from any measurement scale and the

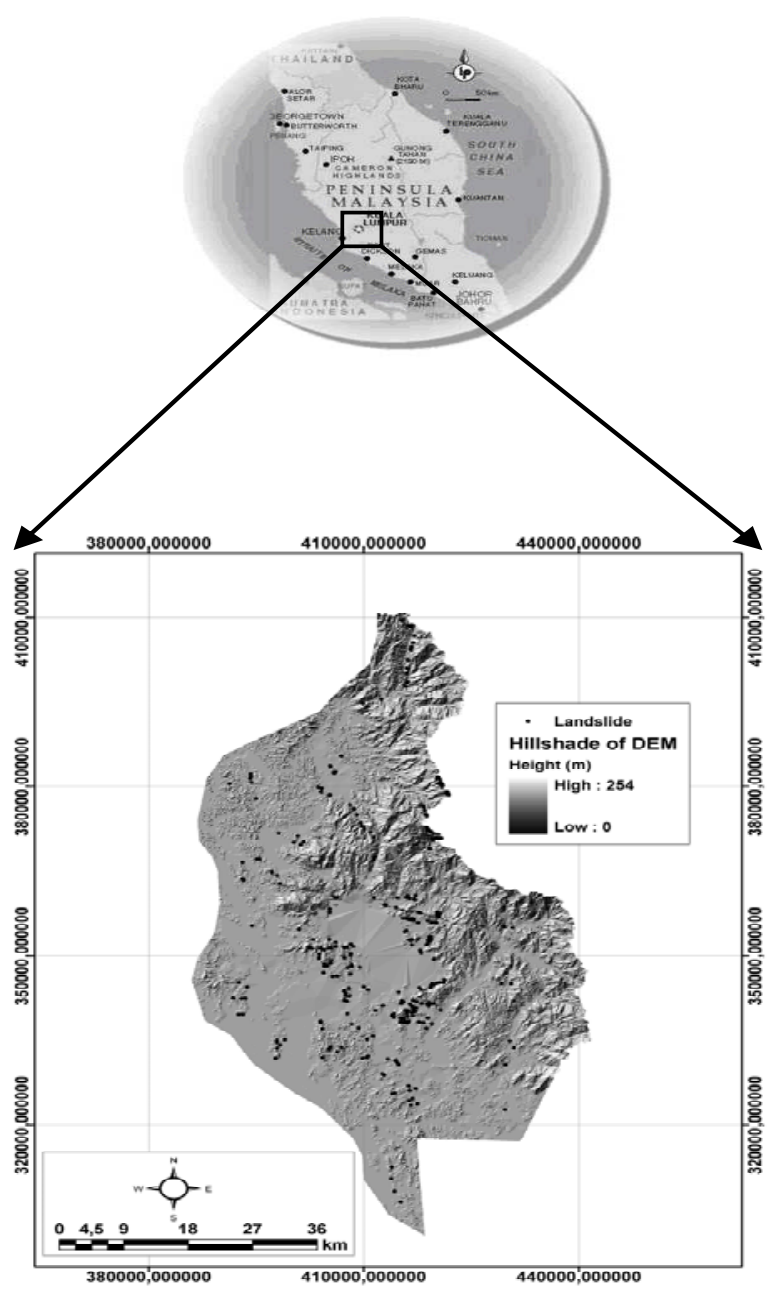

Fig. 1. This is the caption for the figure. If the caption is less than one line then it is centered. Long captions are justified manually.

weighting of evidence is controlled entirely by the expert. The fuzzy logic method allows for more flexible combinations of weighted maps, and could be readily implemented with a GIS modeling language. This is different from data-driven approaches such as weights of evidence or logistic regression, which use the locations of known objects such as landslides to estimate weights or coefficients. The idea of using fuzzy logic in landslide susceptibility mapping is to consider the spatial objects on a map as members of a set. For example, the spatial objects could be areas on an evidence map and the set defined as 'areas susceptible to landslide'. Fuzzy membership values must lie in the range $(0,1)$, but there are no practical constraints on the choice of the fuzzy membership values. Values are 
chosen to reflect the degree of membership of a set, based on subjective judgment. Given two or more maps with fuzzy membership functions for the same set, a variety of operators can be employed to combine the membership values.

Zimmerman (1996) ${ }^{45}$ discussed a variety of combination rules. Bonham-Carter (1994) ${ }^{46}$ discussed five operators, namely the fuzzy and, fuzzy or, fuzzy algebraic product, fuzzy algebraic sum and fuzzy gamma operator. This study uses the five fuzzy operators for combining the fuzzy membership functions.

The fuzzy and is equivalent to a Boolean AND (logical intersection) operation on classical set values of $(1$,$) . It is defined as:$

$$
\mu \text { combination }=\operatorname{MIN}(\mu \mathrm{A}, \mu \mathrm{B}, \mu \mathrm{C}, \ldots)
$$

where $\mu$ combination is the calculated fuzzy membership function, $\mu \mathrm{A}$ is the membership value for map $A$ at a particular location and $\mu \mathrm{B}$ is the value for map B, and so on.

The fuzzy or is like the Boolean OR (logical union in that the output membership values are controlled by the maximum values of any of the input maps. The fuzzy or is defined as:

$\mu_{\text {combination }}=\operatorname{MAX}\left(\mu_{\mathrm{A}}, \mu_{\mathrm{B},} \mu_{\mathrm{C}, \ldots)}\right)$

The Fuzzy Algebraic Product is defined as:

$\mu_{\text {combination }}=\prod_{i=1}^{n} \mu_{\mathrm{I}}$

where $\mu_{i}$ is the fuzzy membership function for the $\mathrm{i}$ th map, and $\mathrm{i}=1,2, \ldots, \mathrm{n}$ maps are to be combined.

The fuzzy algebraic sum is complementary to the fuzzy algebraic product, being defined as:

$\mu_{\text {combination }}=1-\prod_{i=1}^{n}\left(1-\mu_{\mathrm{i}}\right)$

The gamma operation is defined in terms of the fuzzy algebraic product and the fuzzy algebraic sum by:

$\mu_{\text {combination }}=(\text { Fuzzy algebraic sum })^{\lambda} *$ (Fuzzy algebraic product) ${ }^{1-\lambda}$,

where $\lambda$ is a parameter chosen in the range $(0,1)$, and the fuzzy algebraic sum and fuzzy algebraic product are calculated using equations (3) and (4) respectively. In the fuzzy gamma operation, when $\lambda$ is 1 the combination is the same as the fuzzy algebraic sum, and when $\lambda$ is 0 the combination equals the fuzzy algebraic product. Judicious choice of $\lambda$ produces output values that ensure a flexible compromise between the 'increase' tendencies of the fuzzy algebraic sum and the 'decrease' effects of the fuzzy algebraic product.

Like the membership function, the frequency ratio was calculated. The frequency ratio is shown in Table 2 for all factors. The spatial relationships between the landslide location and each landslide-related factor were analyzed by using the probability model-frequency ratio. The frequency ratio, a ratio between the occurrence and absence of landslides in each cell, was calculated for each factor's type or range that had been identified as significant with respect to causing landslides. An area ratio for each factor's type or range to the total area was calculated. Finally, frequency ratios for each factor's type or range were calculated by dividing the landslide occurrence ratio by the area ratio. If the ratio is greater than 1 , the relationship between landslides and the factors is higher and, if the ratio is less than 1, the relationship between landslide and each factor's type or range is lower. Then, the frequency ratio was normalized between 0.00 and 1.00 to create the fuzzy membership value.

The input factors were combined for assigning membership functions. Nine landslide causal factors (slope, aspect, curvature, distance from drainage, soil, distance from lineament, NDVI and land cover) were combined to generate the final susceptibility map using fuzzy operators such as fuzzy and, fuzzy or, fuzzy algebraic product, fuzzy algebraic sum and fuzzy gamma operator. In the case of fuzzy gamma operator, the value of $\lambda$ was set to $0.025,0.05,0.1,0.2,0.3,0.4$, $0.5,0.6,0.7,0.8,0.9,0.95$ and 0.975 to detect its effect on the landslide susceptibility map.

Table 1. GIS data layer of study area

\begin{tabular}{lll}
\hline Spatial Database & Factor & Spatial Database \\
\hline Landslide & $\begin{array}{l}\text { Landslide } \\
\text { Slope } \\
\text { Topographic Map }\end{array}$ & $1: 25,000$ \\
& $\begin{array}{l}\text { Aspect } \\
\text { Curvature } \\
\text { Distance } \\
\text { drainage }\end{array}$ & $1: 25,000$ \\
Drainage Map & from & \\
Soil Map & $\begin{array}{l}\text { Types } \\
\text { Litho types } \\
\text { Distance } \\
\text { Geology Map }\end{array}$ & from $1: 100,000$ \\
lineaments & Land Cover & $30 \mathrm{~m} \times 30 \mathrm{~m}$ \\
NDVI & NDVI & $10 \mathrm{mx} 10 \mathrm{~m}$ \\
\hline
\end{tabular}




\section{Results and discussion}

Using the fuzzy membership function from Table 2 and the fuzzy relations (from Eqs. (1) to (5)), the landslide susceptibility index (LSI) values were computed for the 17 cases including the 13 cases in which the gamma operator was used. The computed LSI values were mapped to allow interpretation such as that illustrated for example in Fig. 2. The values were classified into equal areas and grouped into five classes for visual interpretation. For example, in the case of applying the fuzzy And product, the minimum, mean, maximum and standard deviation values of each LSI are 0.0548, $0.5856,0.9929$ and 0.2609 respectively. In the case of applying the fuzzy algebraic sum, the minimum, mean, maximum and standard deviation values of each LSI are $0.0546,0.5238,0.9701$ and 0.2777 respectively. In the case of applying the gamma operator $(\lambda=0.9)$, the minimum, mean, maximum and standard deviation values of each LSI are 0.0475, 0.6074, 0.9976 and 0.2672 , respectively. Also, in the case of applying the gamma operator $(\lambda=0.8)$, the minimum, mean, maximum and standard deviation values of each LSI are $0.7532,0.9434,0.9434$ and 0.1588 , respectively.
The frequency ratio model depicts the relationship between landslide occurrence and slope (Table 2) shows that steeper slopes have greater landslide probabilities. Below a slope of $8^{\circ}$, the frequency ratio was 0.12 , which indicates a very low probability of landslide occurrence. For slopes above $8^{\circ}$, the ratio was $>1$, which indicates a high probability of landslide occurrence. This means that the landslide probability increases with slope angle. As the slope angle increases, then the shear stress in the soil or other unconsolidated material generally increases. Gentle slopes are expected to have a low frequency of landslides because of the generally lower shear stresses associated with low gradients. Steep natural slopes resulting from outcropping bedrock, however, may not be susceptible to shallow landslides.

In the case of the aspect (Table 2), landslides were most abundant on south-facing and southwest-facing slopes. The frequency of landslides was lowest on eastfacing, and southeast-facing slopes, except in flat areas.

Table 2. Spatial relationships between each factor and landslide and fuzzy membership values

\begin{tabular}{|c|c|c|c|c|c|c|c|}
\hline Factor & Class & $\begin{array}{l}\text { Pixels in } \\
\text { domain }\end{array}$ & Pixel \% & $\begin{array}{c}\text { Landslide } \\
\text { occurrence } \\
\text { points }\end{array}$ & $\begin{array}{c}\text { Landslide } \\
\text { occurrence } \\
\text { points \% }\end{array}$ & $\begin{array}{l}\text { Frequency } \\
\text { ratio }\end{array}$ & $\begin{array}{l}\text { Fuzzy } \\
\text { membership } \\
\text { function }\end{array}$ \\
\hline \multirow{11}{*}{ Slope } & $0^{\circ}$ & 13593532 & 41.29 & 4 & 1.23 & 0.03 & 0.00 \\
\hline & $1 \sim 3^{\circ}$ & 2477185 & 7.52 & 3 & 0.92 & 0.12 & 0.02 \\
\hline & $4 \sim 8^{\circ}$ & 2490574 & 7.57 & 55 & 16.87 & 2.23 & 0.49 \\
\hline & $9 \sim 12^{\circ}$ & 2536839 & 7.71 & 34 & 10.43 & 1.35 & 0.29 \\
\hline & $13 \sim 16^{\circ}$ & 2403719 & 7.30 & 43 & 13.19 & 1.81 & 0.39 \\
\hline & $17 \sim 20^{\circ}$ & 1943819 & 5.90 & 25 & 7.67 & 1.30 & 0.28 \\
\hline & $21 \sim 23^{\circ}$ & 1933459 & 5.87 & 32 & 9.82 & 1.67 & 0.36 \\
\hline & $24 \sim 27^{\circ}$ & 2251344 & 6.84 & 34 & 10.43 & 1.53 & 0.33 \\
\hline & $28 \sim 32^{\circ}$ & 1911594 & 5.81 & 34 & 10.43 & 1.80 & 0.39 \\
\hline & $33 \sim 86^{\circ}$ & 1378122 & 4.19 & 62 & 19.02 & 4.54 & 1.00 \\
\hline & Flat & 12283094 & 37.31 & 2 & 0.61 & 0.02 & 0.00 \\
\hline \multirow{8}{*}{ Aspect } & North & 2585339 & 7.85 & 41 & 12.58 & 1.60 & 0.89 \\
\hline & Northeast & 2643883 & 8.03 & 41 & 12.58 & 1.57 & 0.87 \\
\hline & East & 2582813 & 7.85 & 33 & 10.12 & 1.29 & 0.71 \\
\hline & Southeast & 2615946 & 7.95 & 39 & 11.96 & 1.51 & 0.83 \\
\hline & South & 2602947 & 7.91 & 42 & 12.88 & 1.63 & 0.90 \\
\hline & Southwest & 2585338 & 7.85 & 46 & 14.11 & 1.80 & 1.00 \\
\hline & West & 2556343 & 7.77 & 44 & 13.50 & 1.74 & 0.97 \\
\hline & Northwest & 2464484 & 7.49 & 38 & 11.66 & 1.56 & 0.86 \\
\hline \multirow{4}{*}{ Curvature } & Concave & 57103 & 29.33 & 132 & 40.49 & 1.38 & 0.93 \\
\hline & Flat & 80738 & 41.47 & 56 & 17.18 & 0.41 & 0.00 \\
\hline & Convex & 56844 & 29.20 & 138 & 42.33 & 1.45 & 1.00 \\
\hline & $0 \sim 20 \mathrm{~m}$ & 3537061 & 10.74 & 20 & 6.13 & 0.57 & 0.09 \\
\hline \multirow{9}{*}{$\begin{array}{l}\text { Distance from } \\
\text { drainage }\end{array}$} & $22 \sim 50 \mathrm{~m}$ & 3505922 & 10.65 & 33 & 10.12 & 0.95 & 0.47 \\
\hline & $53 \sim 80 \mathrm{~m}$ & 3317942 & 10.08 & 38 & 11.66 & 1.16 & 0.67 \\
\hline & $82 \sim 120 \mathrm{~m}$ & 3591455 & 10.91 & 53 & 16.26 & 1.49 & 1.00 \\
\hline & $121 \sim 183 \mathrm{~m}$ & 3743192 & 11.37 & 41 & 12.58 & 1.11 & 0.62 \\
\hline & $184 \sim 357 \mathrm{~m}$ & 3177946 & 9.65 & 38 & 11.66 & 1.21 & 0.72 \\
\hline & $358 \sim 804 \mathrm{~m}$ & 3037862 & 9.23 & 23 & 7.06 & 0.76 & 0.28 \\
\hline & $805 \sim 1546 \mathrm{~m}$ & 3090958 & 9.39 & 33 & 10.12 & 1.08 & 0.59 \\
\hline & $1547 \sim 2765 \mathrm{~m}$ & 2972570 & 9.03 & 33 & 10.12 & 1.12 & 0.63 \\
\hline & $2766 \sim 9912 \mathrm{~m}$ & 2945279 & 8.95 & 14 & 4.29 & 0.48 & 0.00 \\
\hline
\end{tabular}




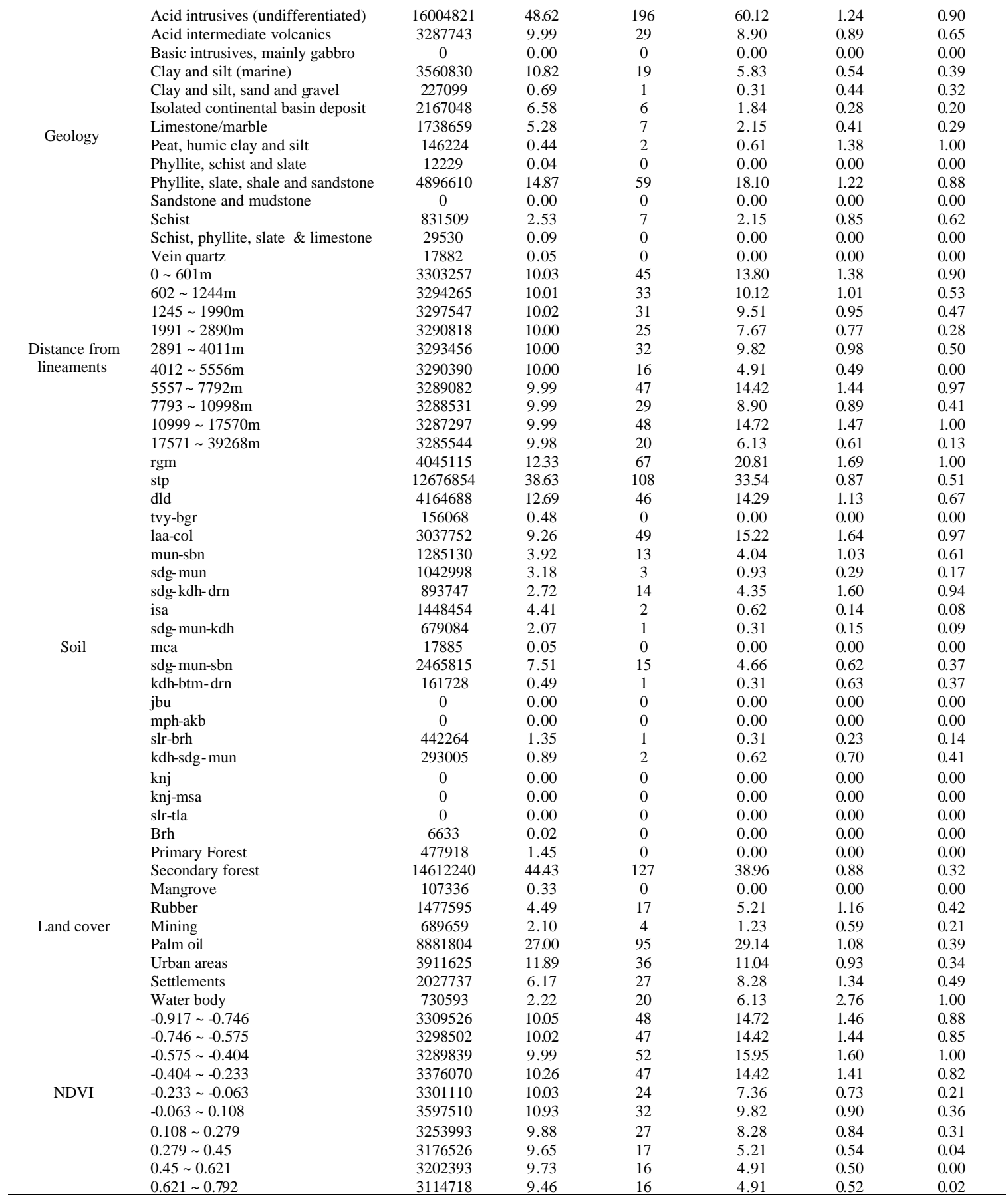

Table 3. Verification results using Receiver Operating Characteristic (ROC) and Area Under Curve (AUC)

\begin{tabular}{lc}
\hline \multicolumn{1}{c}{ Fuzzy Operator } & AUC (\%) \\
\hline Fuzzy And & 84.34 \\
Fuzzy Or & 79.86 \\
Fuzzy Algebraic Sum & 82.39 \\
Fuzzy Algebraic Product & 79.63
\end{tabular}


$\operatorname{Gamma}(\lambda)=0.025$

80.92

$\operatorname{Gamma}(\lambda)=0.05$

$\operatorname{Gamma}(\lambda)=0.1$

$\operatorname{Gamma}(\lambda)=0.2$

$\operatorname{Gamma}(\lambda)=0.3$

$\operatorname{Gamma}(\lambda)=0.4$

$\operatorname{Gamma}(\lambda)=0.5$

Gamma $(\lambda)=0.6$

$\operatorname{Gamma}(\lambda)=0.7$

Gamma $(\lambda)=0.8$

$\operatorname{Gamma}(\lambda)=0.9$

$\operatorname{Gamma}(\lambda)=0.95$

$\operatorname{Gamma}(\lambda)=0.975$
80.92

80.92

80.92

80.92

80.92

80.92

80.92

80.92

83.87

91.30

91.20

91.20
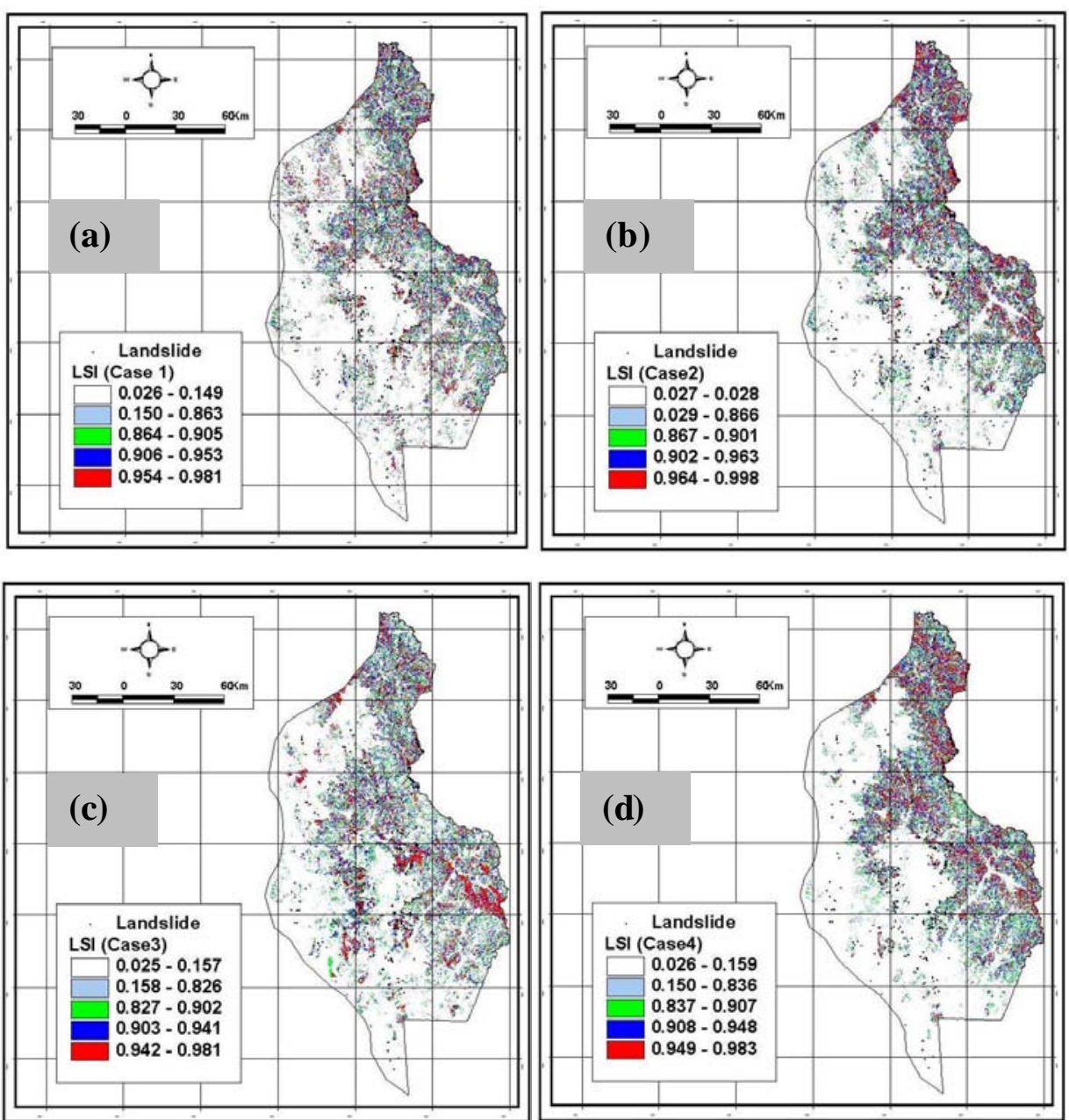


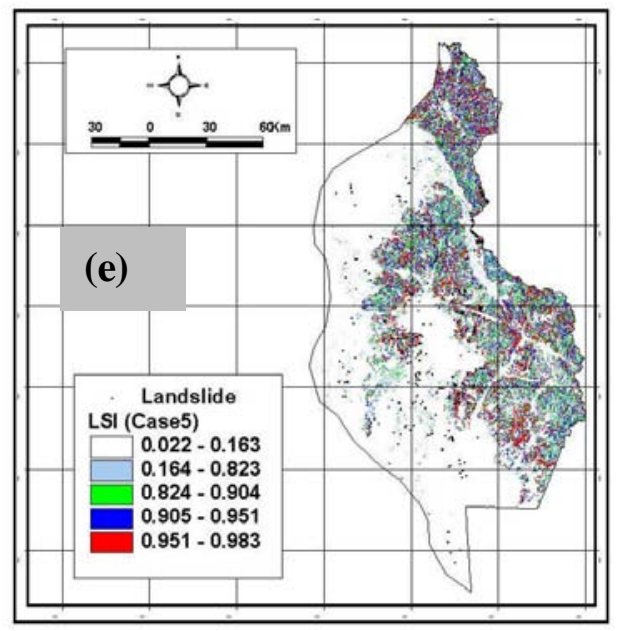

Fig. 2. Landslide susceptibility maps using various fuzzy operators: (a) Application of fuzzy algebraic "sum" operator; (b) Application of fuzzy algebraic "and" operator; (c) Application of fuzzy gamma $(\lambda=0.8)$ operator; (d) Application of fuzzy gamma $(\lambda=0.9)$ operator; and (e) Application of fuzzy ga mma $(\lambda=0.975)$ operator.

The curvature values represent the morphology of the topography. A positive curvature indicates that the surface is upwardly convex at that pixel. A negative curvature indicates that the surface is upwardly concave at that pixel. A value of zero indicates that the surface is flat. As shown in Table 2 from the results of the frequency ratio model, the more positive or negative the curvature value the higher the probability of landslide occurrence. Flat areas had a low curvature value of 0.41 whereas concave shape had highest value of 1.45 . The reason for this is that following heavy rainfall, a convex or concave slope contains more water and retains this water for a longer period which could lead to failure of slope triggering landslide.

Analysis was carried out to assess the influence of drainage lines on landslide occurrence. For this purpose, the proximity of landslide to drainage line was identified by buffering (Table 2). It can be seen from the results of the frequency ratio model that as the distance from a drainage line increases, the landslide frequency generally decreases. At a distance of $<357 \mathrm{~m}$, the ratio was $>1$, indicating a high probability of landslide occurrence, and at distances $>358 \mathrm{~m}$, the ratio was $<1$, indicating very less probability. This can be attributed to the fact that terrain modification caused by gully erosion may influence the initiation of landslides. However, at a distance of $<20 \mathrm{~m}$, the frequency ratio is 0.57 which is due to the less number of previous occurred landslides.
For geological factors using frequency ratio model, such as the lithology (Table 2) and the distance from lineament (Table 2), it was found that in the case of the lithology, the frequency ratio was higher (1.24) in acid intrusive; peat, humic clay and silt; phyllite, slate and shale, and was lower (0.0) in schist and basic intrusive areas. In case of the distance from lineament, the closer the distance was to lineament, the greater was the landslide-occurrence probability. For distances of $<1244 \mathrm{~m}$, the ratio was $>1$, indicating a high probability of landslide occurrence, and for distances of $>1244 \mathrm{~m}$, the ratio was $<1$, indicating a low probability. This means that the landslide probability decreases with increasing distance from lineament. As the distance from lineament decreases, the fracture of the rock increases, and the degree of weathering increases resulting in greater chances of landslides.

In the case of soil using frequency ratio model (Table 2), the landslide-occurrence values were higher in rgm, dld, laa-col series. In the case of landcover (Table 2), the landslide-occurrence values were higher in tin mine and rubber plantation areas. In the case of the normalized differential vegetation index using frequency ratio model (Table 2), for NDVI values below -0.233, the frequency ratio was $<1$, which indicates a low landslide-occurrence probability, and for NDVI values above -0.233 , the frequency ratio was $>1$, indicating a high landslide-occurrence probability. 


\section{Verification of susceptibility maps and success rate curve}

The landslide susceptibility analysis was performed using various fuzzy operators, and the analysis results were verified using Receiver Operating Characteristic (ROC) analysis. ROC analysis is suitable to assess the validity of a model that predicts the location of the occurrence of a class by comparing the predicted image with the actual presence of the class (Pontius, 2001) ${ }^{47}$. The ROC analysis was used to validate the results obtained from the three models. The verification method was performed by comparison of existing landslide data and landslide susceptibility maps. The comparison results are shown in Table 3.

Landslide susceptibility analysis results were verified using known landslide locations. The rate curves were created for three cases of susceptibility maps using the existing landslide location data. The rate explains how well the model and factor predict the landslide (Chung and Fabbri, 1999) ${ }^{48}$. So, the area under curve can assess the prediction accuracy qualitatively. To obtain the relative ranks for each prediction pattern, the calculated index values of all cells in the study area were sorted in descending order. Then the ordered cell values were divided into 100 classes, with accumulated $1 \%$ intervals. The rate verification results appear as a line in Fig. 3. The comparison results are shown in Fig. 3 as a line graph, which illustrates how well the landslide susceptibility maps of nine cases match with respect to the landslides used in constructing those landslide susceptibility maps. To obtain the data for Fig. 3, relative ranks of landslide susceptibility map and landslide occurrence were compared for each case. For this aim, the probabilities were divided into classes of accumulated area ratio \% (X-axis) according to the landslide susceptibility index value ( $\mathrm{Y}$-axis).

For example, when applying fuzzy algebraic sum, the $90 \%-100 \%$ (10\%) class with the highest probability of a landslide contains $32 \%$ and the $80 \%-100 \%$ class (20\%) contains $58 \%$ of the landslides of study area. In the case of applying the fuzzy And product, the 90\%$100 \%(10 \%)$ class with the highest probability of a landslide contains $37 \%$ and the $80 \%-100 \%$ class $(20 \%)$ contains $62 \%$ of the landslides of study area. In the case of the gamma operator $(\lambda=0.9)$, the $90 \%-100 \%(10 \%)$ class with the highest possibility of a landslide contains $62 \%$ and the $80-100 \%$ class $(20 \%)$ contains $92 \%$ of the landslides of study area. In the case of applying the gamma operator $(\lambda=0.8)$, the $90 \%-100 \%(10 \%)$ class with the highest possibility of a landslide contains $40 \%$ and $80 \%-100 \%$ class $(20 \%)$ contains $63 \%$ of the landslides of study area.

To compare the results quantitatively, the areas under the curve were recalculated taking the total area as 1 , which means perfect prediction accuracy (Chung and Fabbri, 1999) ${ }^{48}$. So, the area under a curve can be used to assess the prediction accuracy qualitatively for landslide susceptibility mapping. The area under the curve is shown in Table 3. For example, in the case of applying fuzzy algebraic And, the area ratio was 0.8434 and we could say that the prediction accuracy is $84.34 \%$. In the case of applying fuzzy algebraic sum, the area ratio was 0.6477 and we could say that the prediction accuracy is $82.39 \%$. In the case of applying the gamma operator $(\lambda=0.975)$, the area ratio was 0.9120 and the prediction accuracy is $91.20 \%$. Although, for the first five classes (50 to $100 \%$ ), the gamma operator " 0.9 " is a little better than those from the remainder of the classes $(0-50 \%)$, the gamma operators produced somewhat similar results in all classes.

\section{Conclusions}

Different fuzzy operators and different $\lambda$ values for the gamma operation were tested on the input fuzzy membership functions to generate the most reliable landslide susceptibility map. The membership values assigned to each evidence map also play an important role in the final results. The fuzzy operators used in the first or further steps of analyses also affect the possibilities obtained in the final susceptibility map.

After verification, among the 17 cases, the case of applying the gamma operator $(\lambda=0.9)$, showed the best accuracy $(90.30 \%)$, whereas the fuzzy algebraic product $(79.63 \%)$ and fuzzy or $(79.86 \%)$ operators showed the worst accuracy. In the case of applying the gamma operator with different $\lambda$ value, the prediction accuracy had a similar upward trend value, between $80.92 \%$ and $83.87 \%$. Generally, the verification results showed satisfactory agreement between the susceptibility map and the existing data from landslide locations. The effect of choosing different values of gamma (between 0 and 1) is not large. Because the landslide susceptibility maps using different values of gamma 
(Fig. 3) are very similar and the prediction accuracy after verification is also very similar.

In the study the data derived model (frequency ratio) and the knowledge-derived model (fuzzy logic) were combined. As a result, the combined data and knowledge derived model is useful for landslide susceptibility mapping considering the prediction accuracy. Decision making under uncertainty is closely related to susceptibility analysis. Landslide susceptibility map will help for decision making for planners. These decisions are usually in the form of technical countermeasures, regulatory management or combinations of the two. Classic examples of regulatory management are zoning maps which, for instance, exclude some areas from habitation. Landslide susceptibility maps are of great help to planners and engineers for choosing suitable locations to implement development action plans. Their results can be used as basic data to assist slope management and land-use planning. The models used in the study are valid for generalized planning and assessment purposes, although they may be less useful at the site-specific scale where local geographic and geological heterogeneities may prevail. In spite of a number of weaknesses in the database, the Fuzzy logic modelling approach, combined with the use of remote sensing and GIS spatial data, yields a reasonable accuracy for the landslide prediction. In order to be applied in a more way, more landslide data are needed, as well as applications to more regions.

\section{Acknowledgements}

Thanks are due to Alexander von Humboldt Foundation, Germany for awarding visiting scientist position at Dresden University of Technology.

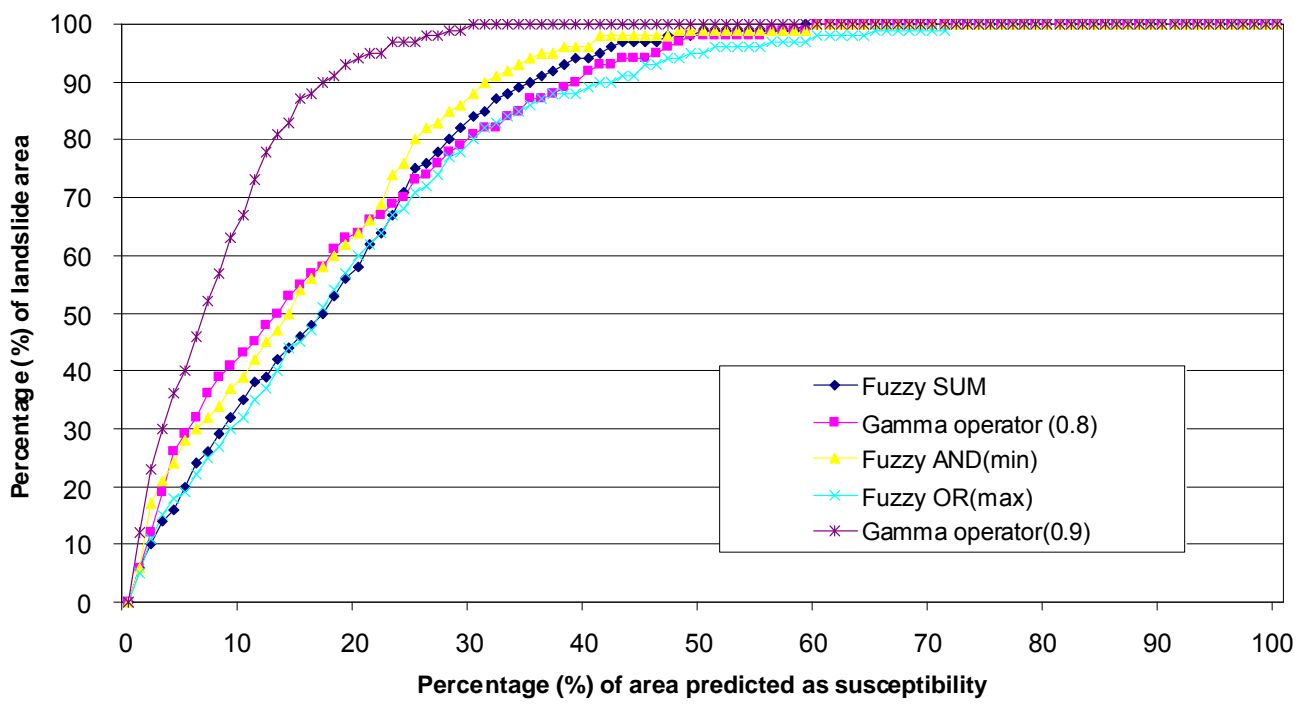

Fig. 3. Success rate evaluation of landslide susceptibility models using area under the curve (AUC).

\section{References}

1. F. Guzzetti, A. Carrarra, M. Cardinali and P, Reichenbach, "Landslide hazard evaluation: a review of current techniques and their application in a multi-scale study. Central Italy", Geomorphology, 31, 181-216 (1999).

2. R. K. Dahal, S. Hasegawa, S. Nonomura, M. Yamanaka, T. Masuda and K. Nishino, "GIS-based weights-ofevidence modelling of rainfall-induced landslides in small catchments for landslide susceptibility mapping". Environ. Geol., 54(2), 314-324(2008).
3. A. Clerici, S. Perego, C. Tellini and P. Vescovi, "A GISbased automated procedure for landslide susceptibility mapping by the Conditional Analysis method: the Baganza valley case study (Italian Northern Apennines)". Environ. Geol., 50, 941-961 (2006).

4. D. Rowbotham and D. N. Dudycha, "GIS modeling of slope stability in Phewa Tal watershed, Nepal". Geomorphology, 26, 151-170 (1998).

5. C. Baeza and J. Corominas, "Assessment of shallow landslide susceptibility by means of multivariate 
statistical techniques". Earth Surf. Processes Landforms, 26, 1251-1263 (2001).

6. S. Lee and K. Min, "Statistical analysis of landslide susceptibility at Youngin, Korea". Environ. Geol., 40, 1095-1113 (2001).

7. A. Clerici, S. Perego, C. Tellini and P.A. Vescovi, "Procedure for landslide susceptibility zonation by the conditional analysis method". Geomorphology. 48, 349364 (2002).

8. S. Lee, J. Choi and K. Min, "Landslide susceptibility analysis and verification using the Bayesian probability model". Environ. Geol., 43, 120-131 (2002).

9. S. Lee, J. Choi and K. Min, "Probabilistic landslide hazard mapping using gis and remote sensing data at Boeun, Korea”. Int. J. Remote Sens., 25, 2037-2052 (2004).

10. S. Lee and B. Pradhan, "Probabilistic Landslide Risk Mapping at Penang Island, Malaysia”. J. Earth Syst. Sci., 115 (6), 661-672 (2006).

11. S. Lee and U. Choi, "Development of GIS-based geological hazard information system and its application for landslide analysis in Korea”. Geosci. J., 7, 243-252 (2003).

12. B. Pradhan, R. P. Singh and M. F. Buchroithner, "Estimation of stress and its use in evaluation of landslide prone regions using remote sensing data". $A d v$. Space Res., 37, 698-709 (2006).

13. B. Pradhan and A. M. Youssef, "Manifestation of remote sensing data and GIS for landslide hazard analysis using spatial-based statistical models". Arabian Journal of Geosciences, doi: 10.1007/s12517-009-0089-2 (article on-line first) (2009).

14. S. Lee and B. Pradhan, "Landslide hazard mapping at Selangor, Malaysia using frequency ratio and logistic regression models". Landslides, 4, 33-41 (2007).

15. S. Lee and N. T. Dan, "Probabilistic landslide susceptibility mapping in the Lai Chau province of Vietnam: focus on the relationship between tectonic fractures and landslides". Environ. Geol., 48, 778-787 (2005).

16. A. M. Youssef, B. Pradhan, A. F. D. Gaber and M. F. Buchroithner, "Geomorphological hazard analysis along the Egyptian Red Sea Coast between Safaga and Quseir". Nat. Hazard. Earth Sys., 9, 751-766 (2009).

17. S. Lee, U. Chwae and K. Min, "Landslide susceptibility mapping by correlation between topography and geological structure: the Janghung area, Korea". Geomorphology, 46, 149-162 (2002).

18. B. Pradhan and S. Mansor, Application of remote sensing data and gis tools for regional landslide hazard analysis at Cameron Highland, Malaysia by using logistic regression model. Proceedings of IEEE International Geoscience and Remote Sensing Symposium, Barcelona, 23- 27 (2007).

19. B. Pradhan and S. Lee, "Delineation of landslide hazard areas on Penang Island, Malaysia, by using frequency ratio, logistic regression, and artificial neural network models". Environ. Earth Sci., doi: 10.1007/s12665-0090245-8 (article on-line first) (2009).

20. B. Pradhan, "Remote sensing and GIS-based landslide hazard analysis and cross-validation using multivariate logistic regression model on three test areas in Malaysia”. Adv. Space Res., doi:10.1016/j.asr.2010.01.006 (article online first) (2010).

21. B. Pradhan and S. Lee, "Landslide susceptibility assessment and factor effect analysis: backpropagation artificial neural networks and their comparison with frequency ratio and bivariate logistic regression modeling". Environ. Modell. Softw., doi: 10.1016/j.envsoft.2009.10.016 (article online first) (2009).

22. G. C. Ohlmacher and J. C. Davis, "Using multiple logistic regression and GIS technology to predict landslide hazard in northeast Kansa, USA”. Eng. Geol., 2157, 1-13 (2003).

23. S. Lee, "Application of logistic regression model and its validation for landslide susceptibility mapping using GIS and remote sensing data". Int. J. Remote Sens., 26, 14771491 (2005).

24. M. C. Tunusluoglu, C. Gokceoglu, H. A. Nefeslioglu and H. Sonmez, "Extraction of potential debris source areas by logistic regression technique: a case study from Barla, Besparmak and Kapi mountains (NW Taurids, Turkey)". Environ. Geol., 54(1), 9-22 (2008).

25. T. Can, H. A. Nefeslioglu, C. Gokceoglu, H. Sonmez and T. Y. Duman, "Susceptibility assessments of shallow earthflows triggered by heavy rainfall at three subcatchments by logistic regression analyses," Geomorphology, 72, no. 1-4, 250-271 (2005).

26. M. T. Lamelas, O. Marinoni, A. Hoppe and J. Riva, "Doline probability map using logistic regression and GIS technology in the central Ebro Basin (Spain)". Environ. Geol., 54(5), 963-977 (2008).

27. B. Pradhan, S. Lee, S. Mansor, M. F. Buchroithner, N. Jallaludin and Z. Khuzaimah, "Utilization of optical remote sensing data and geographic information system tools for regional landslide hazard analysis by using binomial logistic regression model". J. Appl. Remote Sens. , 2, 1-11 (2008).

28. T. Gorum, B. Gonencgil, C. Gokceoglu and H. A. Nefeslioglu, "Implementation of reconstructed geomorphologic units in landslide susceptibility mapping: the Melen Gorge (NW Turkey)," Nat. Hazards, 46(3), 323-351 (2008).

29. C. Gokceoglu, and H. Aksoy, "Landslide susceptibility mapping of the slopes in the residual soils of the Mengen region (Turkey) by deterministic stability analyses and image processing techniques," Eng. Geology, 44, 147161 (1996).

30. S. Lee, J. H. Ryu, K. Min and J. S. Won, "Landslide Susceptibility Analysis using GIS and Artificial neural network". Earth Surf. Processes Landforms., 27, 13611376 (2003). 
31. S. Lee, J. H. Ryu, M. J. Lee and J. S. Won, "Landslide susceptibility analysis using artificial neural network at Boeun, Korea”. Environ. Geol., 44, 820-833 (2003).

32. S. Lee, J. H. Ryu, J. S. Won and H. J. Park, "Determination and application of the weights for landslide susceptibility mapping using an artificial neural network". Eng. Geol., 71, 289-302 (2004).

33. S. Lee and M. J. Lee, "Detecting landslide location using KOMPSAT 1 and its application to landslidesusceptibility mapping at the Gangneung area, Korea". Adv. Space Res., 38, 2261-2271 (2006).

34. B. Pradhan, S. Lee and M. F. Buchroithner, "Use of geospatial data for the development of fuzzy algebraic operators to landslide hazard mapping: a case study in Malaysia. Applied Geomatics, 1, 3-15 (2009).

35. M. Ercanoglu, and C. Gokceoglu, "Assessment of landslide susceptibility for a land slide-prone area (north of Yenice, NW Turkye) by fuzzy approach," Environ. Geology, 41, 720-730 (2002).

36. B. Pradhan, S. Lee and M. F. Buchroithner, "A GISbased back-propagation neural network model and its cross application and validation for landslide susceptibility analyses". Comput. Environ. Urban., doi:10.1016/j.compenvurbsys (on-line first available) (2010).

37. B. Pradhan and S. Lee, "Landslide risk analysis using artificial neural network model focusing on different training sites". Int. J. Phys Sci, 3(11), 1-15 (2009).

38. B. Pradhan and S. Lee, "Regional landslide susceptibility analysis using backpropagation neural network model at
Cameron Highland, Malaysia". Landslides, doi: 10.1007/s10346-009-0183-2 (article on-line first) (2009).

39. B. Pradhan and S. Lee, "Utilization of optical remote sensing data and GIS tools for regional landslide hazard analysis by using an artificial neural network model at Selangor, Malaysia". Earth Sci. Front., 14(6), 143-152 (2008).

40. L. A. Zadeh, Fuzzy sets. Inf. Control., 8:338-253 (1965).

41. R. K. Brouwer, "Fuzzy relational fixed point clustering". Int. J. Comput. Int. Sys., 2(1), 69-82 (2009).

42. E. Zio, P. Baraldi and I. C. Popescu, "From fuzzy clustering to a fuzzy rule-based classification model". Int. J. Comput. Int. Sys., 1(1), 60-76 (2008).

43. Z, Chen and G. Chen, "Building an associative classifier based on fuzzy association rules". Int. J. Comput. Int. Sys., 1(3), 262-272 (2008).

44. P. Vroman, L. Koehl, X. Zeng and T. Chen, "Designing structural parameters of nonwovens using fuzzy logic and neural networks", Int. J. Comput. Int. Sys., 1(4), 329 339 (2008).

45. H. Z. Zimmerman, "Fuzzy sets theory and its applications". Kluwer, Dordrecht. (1996).

46. G. F. Bonham-Carter, "Geographic information systems for geoscientists. Modelling with GIS". (1994).

47. R. Pontius and L. C. Schneider, "Landcover change model validation by an ROC method for the Ipswich watershed, Massachusetts, USA". Agr. Ecosys. Environ., 85, 239-248 (2001).

48. C. F. Chung and A. G. Fabbri, "Probabilistic prediction models for landslide hazard mapping". Photogrammetr. Eng. Remote Sens., 65(12). 1389-1399 (1999). 